\title{
Verification of a cohesive model based extended finite element method for ductile crack propagation
}

\author{
Huan $\operatorname{Li}^{1}$, Lei $\operatorname{Li}^{1}$, Jiangkun Fan², and zhufeng Yue ${ }^{1}$ \\ ${ }^{1}$ Affiliation not available \\ ${ }^{2}$ Northwestern Polytechnical University
}

August 31, 2020

\begin{abstract}
In this study, an approach utilizing a conjunction of the extended finite element method (XFEM) and the GTN micro-mechanical damage model is proposed for predicting the ductile crack propagation of a mill-annealed Ti-6Al-4V alloy. The cohesive model based XFEM approach is used to capture the continuous crack propagation process and the GTN model is applied to describe the constitutive behavior of the material. Simulations are conducted by using the standard finite element code ABAQUS following a Newton-Raphson algorithm solution with employing the user material subroutine of the GTN model. In comparison to the experimental results of the smooth, notched and cracked titanium specimens, this approach is shown to be an efficient method for simulating the ductile crack propagation process under different stress triaxialities.
\end{abstract}

\section{Hosted file}

Manuscript.docx available at https://authorea.com/users/355043/articles/478447-verificationof-a-cohesive-model-based-extended-finite-element-method-for-ductile-crack-propagation 